\title{
Semiocapitalismo, marca y publicidad. Una visión de conjunto
}

\author{
Antonio CARO ${ }^{1}$ \\ Universidad Complutense de Madrid
}

\begin{abstract}
RESUMEN:
El objetivo del presente trabajo es introducir al lector en el modo de producción-consumo que denominamos con el término semiocapitalismo, poniendo de relieve los componentes principales que funcionan en el seno del mismo: el signo/mercancía como su forma elemental; la producción semiótica como en el género productivo que ha sustituido a la producción material como el núcleo de dicho sistema, así como la marca y la publicidad en cuanto instrumentos primordiales de la mencionada producción semiótica. A través de la exposición se pretende una inmersión del lector en el seno de este sistema económico-ideológico, de modo que aquél aprecie por sí mismo hasta qué punto dicho modo de producción-consumo supone una ruptura con el capitalismo productivista analizado en su día por Carlos Marx.
\end{abstract}

PALABRAS CLAVE: semiocapitalismo; signo/mercancía; valor de consumo; producción semiótica; marca; publicidad.

TITLE: Semiocapitalism, brand, and advertising. An overview

\begin{abstract}
:
The purpose of this paper is introducing the reader into the production-consumption mode which we're designating semiocapitalism, emphasizing the main components that work inside: the commodity/sign -its elementary form; the semiotic production -the productive genre that have replaced to material production in the nucleus of this system; and brand and advertising -the fundamental instruments of semiotic production. Through the exposition, the author try to immerse the reader into this economic-ideological system, in order that he or she may appreciate by itself until what level this production-consumption mode implies a rupture with the productive capitalism analyzed by Karl Marx.
\end{abstract}

KEY WORDS: semiocapitalism; commodity sign; consumer value; semiotic production; brand; advertising.

\section{Introducción}

El presente trabajo parte de los siguientes propósitos: 1) iniciar al lector acerca de qué es el semiocapitalismo y cómo este ha llegado a constituirse, desde las primeras décadas del siglo XX, en el modo de producción-consumo dominante, frente al capitalismo productivis-

1 Antonio Caro es profesor titular jubilado de Teoría de la Publicidad en la Universidad Complutense de Madrid. Actualmente colabora con diversas universidades españolas y latinoamericanas en cursos de postgrado. Su último libro publicado es Comprender la publicidad (Barcelona, Blanquerna, 2010). E-mail: antcaro@ono.com. Página web: www.antoniocaro.es 
ta decimonónico analizado por Marx; 2) poner de relieve los componentes primordiales de dicho sistema, como son el signo/mercancía en cuanto su forma elemental y la producción semiótica como su género de producción específico; 3) especificar el papel real que cumple la marca, en cuanto expresión semiolingüística del signo/mercancía, en lo concerniente a expropiar al consumidor de su capacidad para decidir sobre su propio consumo; 4) delimitar la labor que cumple la publicidad en el marco del semiocapitalismo en cuanto escaparate de la marca y, en general, de todo el sistema; y 5) proponer, finalmente, una visión de conjunto del semiocapitalismo, en el marco de la cual signo/mercancía, producción semiótica, marca y publicidad se aglutinan en un todo armónico, que es lo que hace que dicho sistema funcione en la práctica -o más bien haya funcionado hasta la actualidad, habida su presente situación de crisis- como el modo de producción-consumo dominante tras la fase del capitalismo decimonónico productivista.

El texto que aquí se desarrolla se basa en investigaciones previas del autor plasmadas en diferentes trabajos ${ }^{2}$, coincidentes y gran medida inspirados en -aunque progresivamente distanciados de- el «primer Baudrillard» $»^{3}$ : autor del que parte, como es bien sabido, una interpretación del capitalismo desde una perspectiva postmarxiana de la que participan numerosos autores, entre los que vale citar a Sternberg ${ }^{4}$, Goux ${ }^{5}$, Berar$\mathrm{di}^{6}$... Sin olvidar el precedente que en su momento supuso Rossi-Landi ${ }^{7}$, cuya línea de investigación ha proseguido en lo fundamental el también italiano Augusto Ponzio ${ }^{8}$. Con respecto a la marca se ha insistido con frecuencia en su naturaleza semiótica (así, Semprini ${ }^{9}$, Costa $^{10}$, Batey ${ }^{11}$, entre otros), pero sin enfatizar suficientemente en casi

2 CARO, A. (1967): La sociedad de consumo, http://independent.academia.edu/AntonioCaro/Books/ 580765/La sociedad de consumo; (2002): CARO, A. (2002): «Del valor de consumo a la corporación como valor», Sphera Publica. Revista de Ciencias Sociales y de la Comunicación, 2, 65-79, Murcia, Servicio de Publicaciones de la UCAM; CARO, A., ed. (2009): De la mercancía al signo/mercancía. El capitalismo en la era del hiperconsumismo y del desquiciamiento financiero, Madrid, Editorial Complutense, http://www.ucm.es/BUCM/ecsa/36254.php?id=356

BAUDRILlARD, J. (1968): El sistema de objetos, México, Siglo XXI, 1975 (2ª ed.); BAUDRILLARD, J. (1970): La sociedad de consumo. Sus mitos, sus estructuras, Madrid, Siglo XXI de España, 2009; BAUDRILLARD, J. (1972): Crítica de la economía política del signo, México, Siglo XXI, 1974; BAUDRILLARD, J. (1973): Le miroir de la production ou l'illusion critique du materiales historique, Tournai, Casterman, 1977 ( 2 a ed.).

4 StenBerg, E. (1999): The Economy of Icons. How Business Manufactures Meaning, Westport, Preager Publishing.

Goux, J.-J. (200): Frivolité de la valeur. Essai sur l'imaginaire du capitalisme, París, Blusson,.

6 BERARDI, F. (2001): La fábrica de la infelicidad. Nuevas formas de trabajo y movimiento global, Madrid, Traficantes de Sueño, 2003.

7 Rossi-LANDI, F. (1968a): El lenguaje como trabajo y como mercado, Caracas, Monte Ávila, 1970.

8 PonZIO, A. (2011): «La lógica de la publicidad y la ideo-lógica de la comunicación-producción global», en Caro, A.; Scolari, C.A. (coords.), Estrategias globales. Publicidad, marcas y semiocapitalismo, DeSignis 17, Buenos Aires, La Crujía Ediciones, 33-41.

9 SEMPrInI, A. (1992): El marketing de la marca. Una aproximación semiótica, Barcelona, Paidós, 1995; SEMPRINI, A. (2005): La marca postmoderna. Potere e fragilità della marca nelle società contemporanee, Milán, FrancoAngeli, 2006.

10 Costa, J. (2004): La imagen de marca. Un fenómeno social, Barcelona, Paidós. 
ninguno de los casos el lugar que ésta ocupa en el marco del semiocapitalismo en cuanto plasmación de la producción semiótica que, como acabo de indicar, es su género de producción específico, así como tampoco la entidad semiosica que le es propia y que, como veremos, constituye su característica fundamental. En lo que concierne al papel que la publicidad desempeña en el seno de este modo específico de producciónconsumo, hay que referirse a obras clásicas como las de Williamson ${ }^{12}$, Jhally ${ }^{13}$, Wernick $^{14}$ y Goldman y Papson ${ }^{15}$, aunque falta por delimitar con claridad qué significado real reviste el predominio de lo icónico en la publicidad contemporánea y cómo esto repercute en la entidad característica de la marca, en cuanto plasmación a su vez del signo/mercancía.

La idea que preside el presente trabajo es que semiocapitalismo, marca y publicidad forman un continuo estructural cada uno de cuyos elementos remite al resto; de manera que no es posible entender en todas sus dimensiones el mencionado modo de producción-consumo (en cuanto plasmación vigente del sistema capitalista en su tránsito hacia el capitalismo virtual o triunfo definitivo de la fantasmagoría especulativa) si no tenemos en cuenta los elementos primordialmente semióticos, la marca y la publicidad, de los que aquél se vale; como tampoco resulta posible abarcar en todas sus vertientes la actual publicidad y la marca -la cual constituye, como ya he indicado, el constructo semiolingüístico a través de que el signo/mercancía cobra forma- si no las situamos en el marco de ese neocapitalismo

11 Batey, M. (2008): Brand Meaning, Nueva York y Londres, Routledge. [Batey inicia su libro con las siguiente frase: «Though companies create brands identities, people create brand meaning», resaltando de este modo la incidencia del destinatario en la creación de significaciones referidas a las marcas (ibid., XIII).]

Williamson, J. (1979): Decoding Advertisements. Ideology and Meaning in Advertising, Londres y Nueva York, Marion Boyards.

13 Jhally, S. (1987): The Codes of Advertising. Fetichism and the Political Economy of Meaning in the Consumer Society, Londres, Frances Pinter. De Jhally es, tal vez, la mejor descripción del proceso de suplantación y simulación que, como veremos, ejerce el signo/mercancía con relación al producto que está en su base, aunque él lo atribuye de modo reductivo al instrumento publicitario (aparte de sostener una confusión -bastante habitual por lo demás- entre lo simbólico y lo imaginario): «The fetichism of commodities consists in the first place of emtying them through human labour, to make it possible for the imaginary/symbolic social relations to be injected into the construction of meanings at a second level. Production empties. Advertising fills. The real is hidden by the imaginary [curs. orig.]» (ibid., 51).

14 Wernick, A. (1991): Promotional Culture. Advertising, ideology and symbolic expression, Londres, Sage. Tras señalar en el siguiente texto el carácter global de lo que aquí estamos denominando producción semiótica, Wernick se refiere a lo que denomina signo/mercancía: «Artificial semiosis is a multiple practice which occurs at all the points in production, distribution, and exchange at which the commodity imaging process takes shape. [...] The result is a dual-character object, the commodity-sign, which functions in circulation both as an object-to-be-sold and as the bearer of a promotional message. As the latter, it serves to advertise both itself (on the shelf) and (wherever display) all the other produce to which, by brand and style, it is imagistically linked [curs. orig.]» (ibid., 15-16).

15 Goldman, R.; PAPSON, S. (1996): Sign Wars. The Cluttered Lansdscape of Advertising, Nueva York, The Guilford Press; Goldman, R.; PAPSON, S. (1998): Nike Culture, Londres, Sage. [En el primero de los libros citados, los dos autores constatan el surgimiento de un cierto «realismo publicitario» frente a las críticas de que la publicidad «constructed unreal worlds with little relevance for everyday life» (ibid., VI).] 
de naturaleza sígnica, dentro del cual funcionan como los ingredientes semióticos en virtud de los cuales se ha producido, como vamos a ver a continuación, la transición entre un tipo de capitalismo mercantil o productivista gobernado por la dialéctica entre valor de uso y valor de cambio teorizada por Marx y un sistema como el actual, en cuyo seno el signo/marca ocupa el lugar central que antes correspondía al producto material. Abriéndose con ello el deslizamiento hacia lo inmaterial y hacia un género de semiosis aparentemente sin sentido - puesto que carece, como veremos, de fijación simbólica- cuyo resultado final es que la especulación financiera, sin otra referencia que ella misma, ocupe el lugar central que antes correspondía a la economía real, originando de este modo la ruina del propio sistema que estamos experimentando ante nuestros ojos.

Así pues, vamos a examinar a continuación cada uno de estos aspectos.

\section{Qué es el semiocapitalismo ${ }^{16}$}

\subsection{Introducción}

Como se ha señalado repetidas veces, la mercancía, en cuanto componente nuclear del modo de producción capitalista, tiene en sí misma un ingrediente semiótico: bien porque, como plantea Jean Baudrillard, se parte de una radical equiparación entre mercancía y signo o más bien de la subsunción de la mercancía por el signo $^{17}$; bien porque, en términos más pragmáticos, se señalan las concomitancias existentes entre producción e intercambio de mercancías y producción e intercambio de mensajes. Idea esta última que, si ya estaba de algún modo presente en $\operatorname{Marx}^{18} \mathrm{y}$, desde otro punto de vista, también en Saussure ${ }^{19}$, es explícitamente pro-

16 Véanse sobre el tema los ensayos reunidos en la sección primera del volumen colectivo CARO, A.; SCOLARI, C.A. (coords.) (2011): Estrategias globales. Publicidad, marcas y semiocapitalismo, DeSignis, 17, Buenos Aires, La Crujía Ediciones, 15-59, con trabajos de Jean-Joseph Goux, Franco Berardi, Augusto Ponzio, César R. Siqueira Bolaño y Marta S. Sánchez.

17 Para Baudrillard, «la estructura del signo se halla en el corazón mismo de la forma/mercancía [curs. orig.]», en la medida que lo que subyace, en su opinión, tanto tras los «[c]ontenidos materiales de producción» como tras los «contenidos inmateriales de significación» es el código. BAUDRILLARD (1972), Crítica de la economía política..., 171. No obstante, en un texto posterior, Baudrillard añade un cierto matiz diacrónico a esta visión primordialmente sincrónica cuando considera «el paso de la forma/mercancía a la forma/signo» como la «tercera fase de la economía política»; aunque ello implica, en su opinión, «el paso de todos los valores al valor de cambio/signo bajo la hegemonía del código». BAUDRILLARD (1973), Le miroir de la production ..., 100-103. [Sobre el estructuralismo larvado que implica la concepción de Baudrillard, véase CARO, A. (2007): «Jean Baudrillard y la publicidad», Pensar la Publicidad. Revista Internacional de Investigaciones Publicitarias, 1(2), 131-146.]

18 En opinión de Rossi-Landi, «Marx describió por primera vez no solamente el intercambio sino también la producción y el consumo de mercaderías en cuanto mercaderías, es decir, todo el proceso de su funcionamiento como mensajes. [...] La economía marxista, como ciencia que estudia las mercaderías como mensajes y de tales mensajes [...], ofrece el primer modelo dialéctico completo de un proceso comunicativo socialmente real [...]. Precisamente, por excluir la producción y el consumo de los portadores de 
clamada en el ensayo clásico de Ferruccio Rossi-Landi El lenguaje como trabajo y como mercado $(1965)^{20}$ : ya que, según este autor, todo lo que tiene valor y significado es producto del trabajo humano. De lo que se desprende la existencia de una relación inherente entre economía y semiótica que habría de alcanzar su paroxismo en el estadio del semiocapitalismo.

No obstante, y pese a tales antecedentes, el semiocapitalismo implica una ruptura con la tradición anterior: ya que dicha involucración entre economía y semiótica pasa a ser entendida desde la nueva perspectiva, no como equiparación entre mercancía y mensaje o entre mercancía y signo, sino como sustitución y simulación ${ }^{21}$ de la mercancía por su signo. De modo que, si la forma elemental del capitalismo decimonónico analizado por Marx fue la mercancía ${ }^{22}$-de ahí el calificativo mercantilista con que me permito designarlo, pese al confusionismo que pueda implicar el término ${ }^{23}$-, la forma elemental del semiocapitalismo es, como ya he indicado, el signo/mercancia ${ }^{24}$ : entendiendo con dicho término aquel género de mercancía cuya materialidad está subsumida por una dimensión inmaterial, resultado de un específico proceso de producción semiótica que ha desplazado a la producción material como núcleo del proceso productivo. Y así, como consecuencia

esos mensajes, la economía marxista se convierte en una ciencia típicamente semiótica [...] (cus. orig.)». Rossi-LANDI (1968a), El lenguaje como trabajo..., 78.

19 «Son famosas las páginas (y no pocas) en que Saussure compara el valor de los signos al económico $[\ldots]$. Ibidem, 278.

«[...] una mercancía es una mercancía y no solo un producto o un objeto útil, porque es, y en tanto que sea, un mensaje de cierto tipo [curs. orig.]». Rossi-LANDI, F. (1968b): «Las mercancías como mensajes», en Semiótica y estética, Buenos Aires, Nueva Visión, 1976, 104 (103-109). De modo que, como añade en otro lugar, «la economía es el estudio de los mensajes-mercaderías [curs. orig.]». RossI-LANDI, (1968a), El lenguaje como trabajo..., 74 .

21 Como es bien sabido, el concepto de simulación es omnipresente en la obra de Baudrillard. Pero se trata en su caso de una simulación abstracta, en cuanto opuesto metafísico al intercambio simbólico, y que se traduce en el reinado universal del código, una vez que en su opinión se ha producido la subsunción de la mercancía por el signo y, en definitiva, la equiparación de la forma/mercancía con la forma/signo dentro de lo que denomina «ley estructural del valon». Y así, escribe Baudrillard: «[...] toda realidad es absorbida por la hiperrealidad del código y de la simulación. Es un principio de simulación que nos rige en lo sucesivo en lugar del antiguo principio de realidad. Las finalidades han desaparecido, son los modelos los que nos generan. Ya no hay ideología, solo hay simulacros». BAUDRILLARD, J. (1976): El intercambio simbólico y la muerte, Caracas, Monte Ávila Editores, 1980, 6. Posición esta, como se ve, nihilista, que no hace más que reafirmar el orden existente.

${ }^{22}$ Tal como escribe el autor en las primeras líneas de El Capital: «La riqueza de las sociedades en que impera el régimen capitalista de producción se nos aparece como un "inmenso arsenal de mercancías", y la mercancía es su forma elemental. Por eso, nuestra investigación arranca del análisis de la mercancía [curs. orig.]». MARX, K. (1867): El Capital. Crítica de la Economía Política, México, Fondo de Cultura Económica, $4^{\text {a }}$ ed. 1966, tomo I, 3.

23 Este capitalismo mercantilista de que aquí hablamos no tiene obviamente nada que ver con la fase o sistema mercantilista de que hablan los manuales de economía. Véase, por ejemplo, DoBB, M. (1946): «Acumulación de capital y mercantilismo», cap. V de Estudios sobre el desarrollo del capitalismo, Buenos Aires, Siglo XXI Argentina, 1971, 213-262.

24 Cfr. CARO (2009), De la mercancía al signo/mercancía... 
de esta sustitución, el objeto de la producción capitalista ya no es una mercancía material que se intercambia en el mercado en función del valor (trabajo) que la misma implica, sino una seudomercancía inmaterial -si se abstrae la contradicción implícita en la expresión- cuyo valor en el mercado está en relación directa con la producción semiótica desenvuelta en su caso y en la medida que esta se traduce en unas específicas expectativas de consumo. Poniéndose con ello en marcha un proceso de fantasmagorización de la producción capitalista cuya última fase estriba en su actual deriva especulativa.

El semiocapitalismo constituye, en definitiva, el estadio capitalista en el que el signo de la mercancía se hace objeto de la producción sustituyendo a la mercancía y aparentándose como mercancía: esto es, como producto dotado de un valor de uso e intercambiable por consiguiente en el mercado en consonancia con su valor de cambio; cuando en realidad se trata de un ente inmaterial (un signo, en definitiva, que remite a sí mismo como constructo semiósico que es, en el sentido que más adelante veremos) cuya necesidad proviene de la propia producción y que solo llega a alcanzar una determinada demanda en el mercado en virtud de la adhesión obtenida entre sus destinatarios a favor de la significación construida en torno al mismo.

\subsection{El proceso de sustitución de la mercancía por su signo}

Dicho proceso de sustitución-simulación tiene una historia más larga de lo que generalmente se piensa, a la vez que trasciende la socorrida distinción - tras la que se siluetea la sombra del imaginario productivista que caracterizó a aquel capitalismo mercantilista decimonónico y del que participó el propio Marx, tal como demostrara en su día Baudrillard ${ }^{25}$ - entre capitalismo fordista y postfordista ${ }^{26}$.

Concretamente, los inicios del semiocapitalismo se remontan a mediados del siglo XIX, en pleno dominio de lo que estamos denominando capitalismo mercantilista o productivista ${ }^{27}$, para consolidarse y expresar sus verdaderas potencialidades en las décadas iniciales del XX. Y ello cuando, en unas condiciones de oligopoli-

25 «La théorie marxiste, radicale quant à son analyse logique du capital, se soutient par contre d'un consensus anthropologique avec les options du rationalisme occidental, dans la forme définitive qu'il a prise avec la pensée bourgeoise du dix-huitième. Science, technique, progrès, histoire - c'est toute une civilisation qui se ressaisit alors comme productive de son propre développement et qui prend son élan dialectique vers un accomplissement de l'humanité, dessiné en termes de totalité et de bonheur. Genèse, développement, finalité : Marx n'a rien inventé de tout cela, il n'y a changé non plus quant à l'essentiel, quant à l'idée de l'homme se produisant dans sa détermination infinie et se dépassant continuellement vers sa propre fin [curs. orig.]». BAUDRILLARD (1973), Le miroir de la production ..., 22.

26 Distinción esta primordialmente basada en las condiciones de producción y que, en el caso del postfordismo, conecta directamente con el llamado «capitalismo cognitivo». Con respecto a las repercusiones que ambos estadios productivos tienen en el consumo, véase ALONSO, L.E. (2005): La era del consumo, Madrid, Siglo XXI de España.

27 Véase, en un sentido algo distinto del que aquí se plantea, GouX, J.-J. (2011): «El precio de las cosas frívolas», en Caro; Scolari (coords.), Estrategias globales..., 15-23. 
zación y regimentación de la economía capitalista que pusieron fin en la práctica a la «armonía» liberal soñada por Adam Smith ${ }^{28}$, la marca -en cuanto expresión semiolingüística del signo/mercancía- comenzó a ser utilizada por los fabricantes de productos de gran consumo en un sentido distinto al tradicional: no ya como señal adherida a la superficie del producto que garantizaba en función de determinados parámetros su calidad, sino como signo ${ }^{29}$ (más bien icono, en el sentido en que entendía este término el lógico y semiólogo estadounidense Charles Sanders Peirce ${ }^{30}$ ) referido a sí mismo - esto es, capaz de dotarse de su propia significación $^{31}$ - y por consiguiente, de proporcionar al producto una diferenciación ya no basada en sus características o cualidades materiales, sino obtenida como resultado de la mencionada producción semiótica ${ }^{32}$, cuyo objetivo específico es dotar al

28 La obra clásica es BERLE, A.A.; MEAns, G.C. (1932): The Modern Corporation and Private Propiety, Nueva York, Harcourt, Brace \& World. Véase también ChAmBerLIN, E.H. (1931): The Theory of Monopolistic Competition, Cambridge, Mass. y BARAN, P.A.; SwEEzy, P.M. (1966): El capital monopolista, México, Siglo XXI, 1968.

29 Sobre la historia de la marca, véase CosTA (2004), La imagen de marca...

30 «Un Icono - escribe Peirce- es un signo que remite al Objeto que él denota, meramente por virtud de caracteres propios y que posee por igual tanto si tal objeto existe o no [curs. orig.]». PEIRCE, Ch.S. (1987): Obra lógico-semiótica, edición de A. Sercovich, Madrid, Taurus, 249. Ahora bien, como añade el propio Peirce, el icono «no tiene conexión dinámica con el objeto que representa; sucede simplemente que sus cualidades se asemejan a las del objeto y excita sensaciones análogas en la mente para la cual es una semejanza» (ibídem, 273). Pues bien, como veremos más adelante, es este tipo de relación no dinámica y en definitiva no dialéctica entre el icono y su objeto lo que está en la base del género de adhesión no racional que la producción semiótica preconiza entre la marca y su destinatario.

31 Y ello partiendo de una concepción constructivista de la semiótica, en función de la cual un enunciado (ya sea verbal, visual, sincrético o de otro tipo) no se limita en ninguno de los casos posibles a «reflejar» una realidad preexistente. En este sentido, y como señalan Greimas y Courtés, «el mundo extralingüístico, el del "sentido común", está informado por el hombre e instituido por él en significación [...]»; mientras que, por lo demás, «todo discurso $[\ldots]$ se construye su propio referente interno y adopta un nivel discusivo referencial que sirve de soporte a los otros niveles discursivos que él despliega [negrita en orig.]»». Greimas, A.J.; Courtès, J. (1979): Semiótica. Diccionario razonado de la teoría del lenguaje, Madrid, Gredos, 1982, 337.

32 El término producción semiótica guarda numerosas concomitancias, aunque también diferencias, con el de «trabajo de significación» al que se refiere Baudrillard en los siguientes términos: «[...] la fechitización de la mercancía es la del producto vaciado de su sustancia concreta de trabajo y sometido a otro tipo de trabajo, un trabajo de significación, es decir de abstracción cifrada -producción de diferencias y de valores-signos-, proceso activo, colectivo, de producción y de reproducción de un código, de un sistema, investido de todo un deseo desviado, errante, desintrincado del proceso de trabajo real y transferido sobre lo que precisamente niega el proceso de trabajo real. Así, el fetichismo real del objeto se vincula al objetosigno vaciado de su sustancia y de su historia, reducido al estado de marca de una diferencia y resumen de todo un sistema de diferencias». BAUDRILLARD (1972), Crítica de la economía política...., 95. Dicho término guarda igualmente relación con el de «producción icónica» que utiliza Ernest Stenberg, destinada según el autor a «transforming commodities into icons». STENBERG (1999), The Economy of Icons..., 3. También relacionado con dicho término está el de «ingeniería semántica» de que se vale con relación a la publicidad Juan Antonio González Martín, y cuya finalidad según el autor es «enmascarar tanto el universo referencial como su interpretación», impidiendo de esta manera que «el sentido devenga significado». GonZÁlez MarTín, J.A. (1996): Fundamentos para la teoría del mensaje publicitario, Madrid, Fondo de Cultura Económica, 211. Finalmente, Franco Berardi emplea específicamente el término «producción 
signo/mercancía de una significación que ya no está soportada por las características materiales del producto que está en su base. Poniendo así las bases para el funcionamiento de un semiocapitalismo que encuentra en la libertad de significación que de ello resulta su mejor baza.

De hecho, fue en las primeras décadas del siglo XX cuando el marketing -que es la denominación con que se conoce desde la perspectiva empresarial dicha producción semiótica, y cuyo sentido está explícito en la literalidad de su expresión inglesa $^{33}$ - comenzó a ser considerado como la principal actividad de las empresas fabricantes de productos de gran consumo ${ }^{34}$. Hasta el punto de que, en los años sesenta del pasado siglo, un especialista en la materia, Albert W. Frey, no dudó en designar el «despacho de marketing» como «el corazón de la empresa» ${ }^{35}$.

Ahora bien, sustitución de la mercancía por su signo va inextricablemente unida a la simulación del signo como mercancía. Y el marketing viene a constituir el gran operativo capitalista en virtud del cual la mercancía es sustituida por su signo y dotada de una significación artificial simulando que se trata de una mercancía en el estricto sentido del término; proceso este de encubrimiento que atraviesa de arriba abajo la práctica del semiocapitalismo y por cuya mediación lo que es en realidad producción (semiótica) de signos-marcas es aparentado como si se tratara de la producción de mercancías, las cuales responderían en cuanto tales a las necesidades del consumidor y que incluso se valorarían en el mercado -aunque este segundo aspecto suele permanecer en el terreno de las vaguedades- en función del

semiótica» para referirse al proceso de semiotización que hoy experimenta la producción capitalista, pero sin acotar el alcance de dicho término y alternándolo con otros como «trabajo cognitivo», «cognitariado», «semiotrabajo»..., lo cual implica una cierta indefinición por parte del autor con respecto a lo que dicho término designa. Cfr. BERARDI (2001), La fábrica de la infelicidad..., 16.

33 Haciendo mercado: esto es, incrementado la demanda con arreglo a las necesidades de la producción y presionando para ello de forma sistemática sobre sus destinatarios. La mayoría de los tratadistas tratan de maquillar esta realidad desnuda del marketing cubriéndola con toda clase de aderezos basados en una pretendida adecuación entre las necesidades o deseos del consumidor y las disponibilidades de la producción. Más realista es el también tratadista Philip Kotler, quien se limita a constatar que: «El marketing es específicamente concerniente a cómo las transacciones son creadas, estimuladas, facilitadas y valoradas» (cit. Martínez Tercero, M. (1991): «Mercadotecnia», en Benito A. (dir.), Diccionario de Ciencias y Técnicas de la Comunicación, Madrid, Ediciones Paulinas, 924 (923-931)). Sobre la realidad desnuda del marketing, centrada en este caso en el instrumento publicitario, véase la importante obra de Stuart Ewen Captains of Consciousness: Advertising and the Social Roots of the Consumer Society, Nueva York, McGraw-Hill, 1977 (trad. fr. Consciences sous influence. Publicité et genèse de la société de consommation, París, Aubier Montaigne, 1983).

34 Sobre la implantación y expansion de la filosofía del marketing en la sociedad y la cultura de Estados Unidos, véanse, entre otros: STRASSER, S. (1989): Satisfaction Guaranteed. The Making of the American Mass Market, Washington y Londres, Smithsonian Institution Press, 1995; TedLow, R.S. (1990): New and Improved. The Story of Mass Marketing in America, Boston, Harvard Business School Press, 1996; HAMBLETON, R. (1987): The Branding of America, Dublin, New Hampshire, Yankee Books; LEACH,W. (1993): Land of Desire. Merchants, Power, and the Rise of a New American Culture, Nueva York, Vintage Books, 1994.

35 Frey, A.W. (ed.) (1965): Marketing Handbook, Nueva York, The Ronald Press, $2^{\mathrm{a}}$ ed. 
trabajo humano abstracto que aparentemente contienen. Y porque esta sustitución de la mercancía por su signo es indispensable que se mantenga agazapada bajo la añagaza de esa simulación, es por lo que los instrumentos semióticos que son la marca y la publicidad resultan tan imprescindibles para el funcionamiento del semiocapitalismo. Porque reconocer la verdad desnuda del marketing y de la producción semiótica, tal como actúan en el seno de este sistema, equivaldría pura y simplemente a su derrumbamiento.

\subsection{Más allá de la perspectiva marxista}

Dicha sustitución de la mercancía por su signo que es la esencia del semiocapitalismo y su correspondiente simulación constituye la novedad radical que ha empantanado prácticamente desde hace un siglo los estudios críticos sobre el sistema capitalista planteados desde la perspectiva marxista, así como las iniciativas tendentes a la superación de dicho sistema ${ }^{36}$.

Como señalara Marx, la mercancía -en cuanto núcleo del capitalismo mercantilista decimonónico- presupone la existencia de un producto dotado de valor de uso que se va a intercambiar en el mercado por su valor de cambio medido en la cantidad de trabajo humano abstracto de la que aquél es depositario. Pues bien, es este planteamiento canónico -que el catecismo marxista sigue recitando como un mantra- lo que el semiocapitalismo pone en cuestión en todos sus extremos.

En primer lugar, frente a la utilidad (valor de uso) de la mercancía que antece$d e$ a la producción y que se da por supuesta conforme el producto en que aquélla se encarna se corresponde con una necesidad socialmente constituida, la «necesidad» del signo/mercancía y su consecuente utilidad es -como ya señalara John K. Galbraith en los años cincuenta del pasado siglo- «el fruto de la producción»; de modo que esta, añade el mismo autor, «solo viene a llenar el hueco que ella misma ha creado» ${ }^{37}$.

36 Como sería fácil demostrar, la «simulación metafísica» de Baudrillard (véase la nota 21) se sitúa al margen de cualquier perspectiva histórica y no apunta, en ningún caso, a la superación del orden existente, sino más bien a su disolución: «Contra un sistema hiperrealista la única estrategia es patafísica, en cierta forma "una ciencia de soluciones imaginarias", es decir, una ciencia-fícción del vuelco del sistema contra sí mismo en el límite extremo de la simulación, de una simulación reversible en una hiperlógica de la destrucción y de la muerte». BAUDRILLARD (1976), El intercambio simbólico..., 9. En cualquier caso, y desde el punto de vista que aquí sostenemos, el elemento decisivo del semiocapitalismo es la sustitución de la mercancía por su signo, mientras que la simulación del signo como mercancía constituye como hemos visto su encubrimiento.

37 Galbraith, J. K. (1957): La sociedad opulenta, Barcelona, Ariel, $1963^{2}$, 152. En palabras de un autor más reciente, «[...] cada vez es más difícil saber, a nivel individual y a excepción de una restringida élite, qué necesidades podemos expresar de modo autónomo, dado que las necesidades son creadas ad hoc sobre la base de imaginarios preconstituidos y controlados [curs. orig.]». FuMAGALLI, A. (2007): Bioeconomía y capitalismo cognitivo. Hacia un nuevo paradigma de acumulación, Madrid, Traficantes de Sueños, $2010,215$. 
En segundo lugar, en la medida que lo que se intercambia en el mercado dicho con más precisión y en función del nuevo contexto, lo que la producción capitalista pone a disposición de lo que Jean Baudrillard ha denominado con una fórmula feliz «consumidores-fuerza productiva» ${ }^{38}$, a la vez que los «obliga» a consumirlo- son signos (marcas) y no mercancías en el sentido marxiano del término, la cantidad de trabajo humano necesaria para su producción ya no puede ser la medida de su valor. (Como ha señalado Franco Berardi con relación a las nuevas condiciones productivas: «Es cada vez más difícil definir el precio sobre la base del valor y el valor a partir del tiempo de trabajo necesario» ${ }^{39}$.) Y ello se patentiza en el hecho de que, como hemos visto, en el seno del semiocapitalismo el lugar central del proceso productivo ya no lo ocupa la producción material destinada a conferir un valor de uso al producto sobre el que basar el valor de cambio de la correspondiente mercancía, sino la mencionada producción semiótica, no cuantificable en cuanto tal en unidades de trabajo y cuya labor específica consiste en conferir valor a los signos/mercancías al margen de los simulacros de mercancías que estos aparentan y en función de la significación añadida ${ }^{40}$ que se ha decidido asignarles: valor, por tanto, ya no proveniente de aquella cantidad de trabajo material que hacía a la mercancías intercambiables con otras en el mercado (o su equivalente en dinero), sino de las expectativas de consumo generadas a favor de un determinado signo/marca en paralelo a la entidad (semiósica $)^{41}$ que es propia, como más adelante veremos, de aquella significación añadida, y cuyo destinatario básico es el consumidor-fuerza productiva.

De este modo, frente al valor de cambio propio de las mercancías medido en términos de cantidad de trabajo humano abstracto, el valor propio de los signos/mercancías es un neonato valor de consumo ${ }^{42}$ medible en función de aquellas expectativas. Valor, por consiguiente, semiótico - esto es, generado en el proceso mismo de su producción, sin remitir a un antecedente del que constituiría su «reflejo ${ }^{43}$ - puesto que lo que mide es la viabilidad de un determinado signo/mercancía para superar a su competencia en el mercado como resultado de dicha significación prestada: de manera que el valor de consumo de un signo/mercancía, tal como se plasma en el precio que alcanza el producto que a su vez constituye su soporte (al

38 BAUDRILlARD (1970), La sociedad de consumo..., 86-89.

39 BERARDi (2003), La fábrica de la infelicidad..., 126. Como señala por su parte Fumagalli valiéndose de la desfasada terminología marxista: «¿Hasta qué punto es posible, a día de hoy, distinguir dentro de una jornada laboral el tiempo socialmente necesario para producir valor de cambio del empleado para producir valor de uso?». FuMAGALLI (2007), op. cit., 269.

40 Cfr. CARO (1993): La publicidad de la significación (Marco, concepto, taxonomía), tesis doctoral, Madrid, E-Prints Complutenses, 2002, 231-264; http://eprints.ucm.es/1788/

${ }_{41}$ Cfr. CARO, A. (2011): «Marca y entidad semiósica», en Caro, A.; Scolari, C.A. (coords.), Estrategias globales..., 99-104; CARO, A (1993): «Publicidad de la significación y entidad semiótica», cap. 4 de la II parte de La publicidad de la significación..., 231-264.

${ }^{42}$ Cfr. CARO (1967), La sociedad de consumo...; CARO (2002): «Del valor de consumo...».

43 Véase la nota 31. 
igual que el valor de uso del producto era el soporte del valor de cambio de la mercancía en el marco del capitalismo mercantil y productivista analizado por Marx), está definitoriamente distanciado tanto del trabajo abstracto necesario para su producción como de sus cualidades materiales y de la utilidad mayor o menor que suponga para sus consumidores o usuarios ${ }^{44}$.

Por lo demás, conviene insistir, tales cambios tienen lugar en el marco de una situación económica completamente distinta a la analizada por Marx; de modo que si, en su caso, se trataba de medir (en términos de valor de cambio) la intercambiabilidad de las mercancías en el seno de una economía «liberal» donde «todo el mundo» podía ofertar y demandar bienes (el genio de Marx se puso de relieve cuando precisó que el «bien» a ofertar por parte del proletariado estaba restringido a su propia fuerza de trabajo, en cuanto índice de su posición contradictoria dentro del sistema capitalista), en el caso del semiocapitalismo el «mercado» está escindido desde el principio, como vimos, entre un número limitado de empresas que dominan en condiciones de oligopolio los mercados de productos de gran consumo los cuales constituyen el grueso de la producción (flanqueadas por una inversión pública y unas estructuras financieras y servicios de seguridad que hacen posible su funcionamiento, así como por una industria de la guerra concebida como complemento y plataforma de reserva frente a las vicisitudes que puedan experimentar aquellos mercados) y un ejército siempre en expansión de consumidores/fuerza productiva que responde con mayor o menor fidelidad a la presión que el complejo marketing/publicidad -a su vez instrumentos primordiales de la producción semiótica- ejerce sistemáticamente sobre ellos.

Es así como el semiocapitalismo supone una ruptura radical con el capitalismo mercantilista analizado por Marx. Si en su caso se trataba de intercambiar todo tipo de bienes en el mercado - aunque el bien intercambiado consistiera en la fuerza de trabajo- partiendo de la utilidad (valor de uso) que éstos implicaban y conforme incluían un «trabajo abstracto» que los hacía equiparables y por consiguiente intercambiables en el mercado en función de su valor (trabajo) intrínseco, en el caso del semiocapitalismo se trata de incentivar desde la producción el consumo de unos productos cuya presunta utilidad es controlada y clausurada por la propia $\operatorname{producción}^{45}$ (de modo que ya no

44 Esta dependencia del precio de los productos de las expectativas de consumo generadas en torno al signo-marca en el ámbito del semiocapitalismo es lo que proclaman de modo más bien cínico los expertos de marketing, como se pone de relieve en el siguiente texto: «¿Cuál es el precio adecuado?, es una pregunta que con frecuencia formulan quienes tienen la responsabilidad de establecer los precios de los productos y servicios que están comercializando. La pregunta sería más adecuada presentándola así: “¿Cuánto considera usted que pagará por este artículo? o "¿cuánto debemos pedir por lo que vendemos?». STANTON, W.J. $\left(1984^{7}\right)$ : Fundamentos de mercadotecnia, México, McGraw-Hill, 1985 ( $3^{\mathrm{a}}$ ed.), 279. De modo que, como viene a decir este tratadista, el precio de un producto que constituye el soporte material de un signo/mercancía consiste estrictamente en lo que está dispuesto a pagar el consumidor.

45 Como es bien sabido, el producto constituye uno de los ingredientes primordiales de cualquier acción de marketing, tan manipulable y aleatorio como todos los demás (precio, promoción, distribución...). Y lo que hacen en la práctica los operadores de marketing es acondicionar el producto en sus diferentes 
responde, como se daba por supuesto en el primer caso, a una necesidad previamente existente) y cuyo valor está en relación directa con una producción semiótica que, como hemos visto con anterioridad, sustituye a la producción material como núcleo del proceso productivo; producción semiótica la cual se especifica en cada caso en un signo/mercancía que, a su vez, sustituye a la mercancía y la simula en los términos indicados como si en su base existiera un producto que responde a una específica «necesidad» y cuya utilidad lo hace demandable en el mercado en función de la decisión «libre» del consumidor; cuando, como igualmente vimos, la demanda existente hacia un determinado signo/mercancía medible en las expectativas que se concretan en su valor de consumo constituye en realidad la respuesta más o menos pasiva del consumidor/fuerza productiva a la incentivación generada a su favor por la producción (semiótica), tal como se plasma en virtud de su adhesión mayor o menor a la entidad semiósica propia de la marca, mediante la que el signo/mercancía se dota de existencia ${ }^{46}$. $\mathrm{Y}$ es así como el semiocapitalismo supone una ruptura radical con el capitalismo mercantilista que, como manifiesta el propio análisis de Marx, participaba de los principios económicos comunes a prácticamente todos los sistemas productivos sucedidos a lo largo de la historia de la humanidad ${ }^{47}$ (y para todos los cuales la producción venía a satisfacer unas necesidades sociales -con independencia de la índole de las mismasque antecedían como tales a la producción); principios estos que, como acabamos de ver, se rompen cuando el semiocapitalismo suplanta la mercancía por su signo (erigiendo así un velo entre el producto y su apariencia que actúa en detrimento de la libertad individual para decidir los propios comportamientos de consumo); antepone una neonata producción semiótica a la producción material que se había considerado como la única producción realmente existente y humanamente concebible en todos los regímenes económicos precedentes; y sustituye el valor trabajo como medida de lo producido por un fantasmal valor de consumo que consiste en último término en la respuesta

variables -utilidad, novedad, diseño, apariencia, envase...- de modo que despierte del mejor modo posible la adhesión del consumidor hacia la marca a través de la cual el signo/mercancía funciona como verdadera entidad económica.

46 Conviene, para evitar equívocos, despejar el presente cuadro de cualquier sombra de determinismo. No es que la producción semiótica ejercida sobre un determinado signo/mercancía (a través de su expresión semiolingüística en forma de marca) obtenga en todos los casos unas expectativas de consumo que lo doten de un valor sin parangón con el producto material que está en su base, sino que esta es la norma que siguen los productos de gran consumo en el semiocapitalismo con independencia del éxito o fracaso que obtengan en cada caso. Como saben bien los expertos en marketing y como sucede por lo demás en cualquier actividad humana, los éxitos abundan menos que los fracasos. Pero esto no impide constatar que actuar sin atenerse a esta norma dentro del semiocapitalismo - con todos los matices que, sin embargo, incorpora- equivale a estrellarse contra un muro.

47 Punto de vista este que convendría, sin embargo, matizar con relación al capitalismo como un todo, en la medida que, como escribe Moishe Postone: «El objetivo de la producción en el capitalismo no son ni los bienes materiales producidos, ni los efectos reflexivos de la actividad laboral, sino el valor, o más precisamente, el plusvalor». PosTONE, M. (2003): Tiempo, trabajo y dominación social. Una reinterpretación de la teoría crítica de Marx, Madrid, Marcial Pons, 2006, 250. 
definitoriamente condicionada por parte del consumidor/fuerza productiva a las expectativas de demanda que la propia producción (semiótica) ha generado.

\subsection{Del semiocapitalismo al capitalismo virtual}

Ahora bien, es este valor fantasmal característico del semiocapitalismo el que abre las puertas al proceso de virtualización que caracteriza al actual capitalismo, tal como se patentiza en su vertiente crecientemente especulativa y financiera, y ello en la medida que, como señalara el sociólogo español Alfonso Ortí, «la significatización de la economía conduce directamente a su financiarización ${ }^{48}$. Proceso éste que forma parte de un fenómeno mucho más global: el capitalismo virtual como tercera emergencia histórica del modo de producción capitalista y que plantea, como reacción al hiperconsumismo desmedido que ha caracterizado la última fase del semiocapitalismo ${ }^{49}$, la transformación de la «obligación de consumir» propia como hemos visto del semiocapitalismo- en el derecho a consumir que unos neoconsumidores, cada vez más distanciados de las características del consumidor/fuerza productiva, ejercen de modo creciente frente a las presiones de la producción ${ }^{50}$; como también implica la pérdida por parte de la producción capitalista de la clausura informativa que le permitía fijar de manera prácticamente autónoma y por intermedio de la producción semiótica la «necesidad» y consiguiente «utilidad» de lo producido. Todo lo cual plantea un nuevo escenario socio-semioeconómico que aquí solo podemos plantear de pasada ${ }^{51}$ y cuyas virtualidades están alumbrando en el marco de la situación de crisis del sistema que estamos viviendo.

Y una vez que hemos examinado en la presente sección las peculiaridades del semiocapitalismo que permiten sostener que se trata de un modo de producciónconsumo cualitativamente distinto al capitalismo mercantil-productivista analizado por Marx, vamos a referirnos en las dos siguientes a los principales instrumentos de acción de que dispone dicho sistema, como son la marca y la publicidad.

\section{La marca como expresión semiolingüística del signo/mercancía}

Como hemos visto en la sección anterior, la marca constituye el constructo semiolingüístico a través del cual el signo/mercancía se dota de realidad; y devenido en consecuencia artefacto socioeconómico, es capaz de intervenir en las instancias

48 Cfr. CARO, A. (2009a): «Prefacio», en Caro, A., (ed.): De la mercancía al signo/mercancía..., 11 nota (4-15).

49 Cfr. Lipovetsky, G. (2006): La felicidad paradójica. Ensayo sobre la sociedad de hiperconsumo, Barcelona, Anagrama, 2007.

50 Cfr. CARO, A. (2010b): «Editorial. Consumo y crisis capitalista», Pensar la Publicidad, 4(1), 9-14.

51 Véase CARO, A. (2009b): «Conclusión: El capitalismo en la era del hiperconsumismo y del desquiciamiento financiero», en Caro, A., (ed.): De la mercancía al signo/mercancía..., 121-135. 
primordiales de las actuales sociedades capitalistas, hasta constituir el tótem por antonomasia que irradia en el conjunto todo del imaginario vigente en las mismas ${ }^{52}$.

Aunque, como veíamos en la introducción de este trabajo, la naturaleza semiótica de la marca se ha señalado con frecuencia, no se ha insistido lo suficiente en su entidad semiósica como antes he indicado: esto es, un tipo de entidad que no refiere a un significado previamente convencionalizado -y que, por tanto, se independizaría en alguna medida de la marca específica haciéndola referir a un universo semántico del cual el destinatario tendría pleno dominio-, sino que se mantiene en la proximidad icónica del signo con su objeto en el sentido que lo entiende Peirce, de modo que «no tiene conexión dinámica con el objeto que representa; sucede simplemente que sus cualidades se asemejan a las del objeto y excita sensaciones análogas en la mente para la cual es una semejanza» ${ }^{53}$.

Este es precisamente el tipo de semiosis que la marca vigente actúa con su objeto, el producto o servicio al que semiotiza. No una semiotización en el sentido pleno del término - dotándolo de una significación que, como se sostiene habitualmente, lo diferencia de la competencia y lo dota de entidad propia-, sino una semiosización si se me permite el neologismo en virtud de la cual el signo-marca presenta el producto o servicio sin referirlo específicamente a sus cualidades materiales o simbólicas, sino manteniéndolo en ese terreno de nadie de la inmediatez icónica donde el signo-marca está en condiciones de seducir o fascinar a su destinatario, pero se preserva del ejercicio crítico, del alejamiento dialéctico que este puede ejercer sobre aquél, precisamente porque se encuentra inmerso en esa inmediatez de la presentación sígnica frente a la cual solo cabe acatamiento o adhesión, cuando no rechazo tan irracional como las actitudes anteriores; pero no en todo caso ejercicio de una dilucidación racional, en virtud de la cual el objeto marcado pueda ponerse en relación con las necesidades de su destinatario, o de la utilidad real que aquél revista para este ${ }^{54}$.

Tal es la razón de que, como se ha señalado repetidamente, la presencia del icono se haya impuesto de manera prácticamente incontestable a la representación simbólica y a la distancia dialéctica que implica por su parte la expresión verbal, dentro de ese instrumento por antonomasia de la construcción semiósica de la marca que es la publicidad. El icono, como viene a señalar Peirce, carece de profundidad simbólica. Se mantiene simplemente en la superficie del objeto al que refiere estrictamente en función de su semejanza, pero sin decir nada acerca de él, sin afirmar siquiera su existencia o su inexistencia, porque su proximidad con el mismo le impide siquiera postular que se trata de algo real o ficticio. Mera transparen-

52 CARO, A. (2010a): Comprender la publicidad, Barcelona, Blanquerna Tecnologia i Serveis, 67.

53 PEIRCE (1987), op. cit., 273.

54 Esta es la razón por la que un gestor de marcas como Kevin Roberts preconiza que el principal atributo que deben tener lo que denomina lovemarks es el misterio. ROBERTS, K. (2004): Lovemarks. El futuro más allá de las marcas, Barcelona, Ediciones Urano, 2005, 81-102. 
cia del objeto que ha tenido, tal vez, su mejor expresión en el arte parapublicitario de Andy Warhol.

De ello se deduce que la mejor publicidad de marca no dice nada sobre su objeto. Simplemente lo muestra, lo presenta a través de una escenificación necesariamente idealizada, de modo que la única reacción lógica por parte de su destinatario es adherirse a esa escenificación; reconocerse a sí mismo al trasluz de esa modelización postiza y, como consecuencia, prestar su adhesión, probablemente sin saberlo, al signo-marca, el cual se reviste de una sublimidad inalcanzable en función de esa escenificación publicitaria.

Es así como la marca se dota de realidad en el seno del moderno semiocapitalismo. La marca, estricta proximidad icónica en el marco de su escenificación publicitaria y objetual ${ }^{55}$, se impone al destinatario a través de su estricta presencia. No importa qué necesidad vienen a cumplir los productos aureolados por su marca, no importa qué utilidad supone para su destinatario un nuevo teléfono móvil dotado de más gadgets que sus precedentes. Lo que importa es que la presencia de esa marca se ha impuesto en el imaginario social, por mediación de los variados instrumentos que hoy intervienen en su configuración y renovación constantes (los mass media, la publicidad, la labor de los expertos y prescriptores, los mecanismos más o menos ocultos que manejan la obsolescencia programada...). Presencias de marcas sin razón alguna que las justifique; presididas simplemente por una renovación continua, en virtud de la cual nuevas presencias sin orden ni concierto van sustituyendo a las anteriores. De modo que este carrusel interminable alimente indefinidamente tanto la producción como el consumo.

Ahora bien, la razón de esta presencia inmarcesible de la marca en el seno del semiocapitalismo resulta clara. A través de la producción (semiótica) de un conjunto de marcas que se han ido distanciando progresivamente del producto, el semiocapitalismo está más cerca que nunca del sueño de la producción por la producción -en cuanto trasunto del beneficio por el beneficio- que ha aleteado desde siempre tras el imaginario capitalista ${ }^{56}$. Una producción (semiótica) de marcas que ha reducido la producción material a simple prerrequisito -y ahí está para demostrarlo el fenómeno de la virtualización empresarial y de la externalización urbi et orbe de prácticamente todas las labores productivas- es la condición sine qua non para que pueda erigirse un género de producción al margen de las necesidades sociales, o que hace de estas necesidades -como veíamos en la sección segunda- el fruto de la producción. Ahora bien, subordinar la necesidad del producto a la presencia de la

55 Y ello teniendo en cuenta que, como señala Andrew Wernick, ese ejercicio semiótico (artificial semiosis) abarca todo el conjunto de materiales y superficies (envases, embalajes, diseño del producto, superficies de venta, publicidad...) mediante los cuales se promociona un signo/mercancía. WERNICK (1991), Promotional Culture... 15-16.

56 Como lo escribe Postone: «Lo que caracteriza al capitalismo es que, en un nivel sistémico más profundo, la producción no es para el consumo, sino que está dirigida, en última instancia, por un sistema de obligaciones abstractas constituidas por el carácter dual del trabajo en el capitalismo, sistema que establece la producción como su propio objetivo». POSTONE (2003), op. cit., 254. 
marca constituye el mejor ejemplo, sin parangón probablemente en la historia, de una producción que ha hecho de sí misma, de su preservación y expansión incesante contra viento y marea, su propio objeto autorreferencial. Conforme la presencia de la marca se impone a la necesidad del producto, ya no hay razón para subordinar la producción a otra finalidad al margen de ella misma. Por lo demás, en el marco del semiocapitalismo, la autorreferencia de la producción tiene su reflejo exacto en la autorreferencia del consumo. Se consume porque sí exactamente por la misma razón por la que se produce porque sí, sin otra finalidad que el beneficio empresarial que va asociado a esa carrera interminable. Y si la razón de la producción es así una producción y un consumo carentes de razón, el único valor de lo producido es, como antes veíamos, un valor de consumo que no tiene otro valor que las expectativas logradas entre sus destinatarios como resultado de la mencionada producción semiótica; producción esta que, como igualmente vimos, ha sustituido a la producción material como fuente de valor y que se plasma en esas marcas inmateriales, meramente presentes pero privadas de cualquier densidad simbólica.

Todo esto, como es obvio, tiene los días contados. La presencia de las marcas carentes de espesor simbólico tiende a desvanecerse cuando las necesidades materiales perentorias se imponen en el escenario ciudadano y cuando la economía, por otra parte, conoce un proceso de virtualización especulativa que deja en juego de niños esa imposición de la marca virtual frente al producto real. En todas partes la marca constructo semiósico conoce así una situación de crisis que está en relación directa con la tesitura a la que se enfrenta en la actualidad el capitalismo: bien hacia una virtualización completa que conduce con toda probabilidad a la ruina del sistema, bien hacia una reconversión que haga resurgir la representación simbólica del producto frente a la presencia icónica de la marca. Doble bifurcación esta cuyo desenlace es hoy por hoy imprevisible, pero que hará probablemente que los días felices de la marca lleguen a ser, más pronto que tarde, un recuerdo tan añorado por algunos como probablemente detestado por la gran mayoría.

\section{El doble publicitario}

¿Y qué papel cumple la publicidad en el seno del semiocapitalismo? También de lo anterior resulta claro: la publicidad constituye el escaparate a través del cual la marca, y a su trasluz el signo/mercancía, se hacen presentes en la iconosfera contemporánea y por eso se dotan de una contundencia que los hace deseables para cualquier destinatario. ¿Qué tipo de publicidad? Cualquier publicidad. Esto es: obviamente los anuncios de publicidad pagada que pueblan los mass media y cualquier escenario ciudadano, pero también los logosímbolos de marcas prestigiosas que ostentan los famosos en sus escenificaciones mediáticas y espectaculares, como así mismo las recreaciones publicitarias que ejercen los usuarios en YouTube o 
cualquier sitio web y que implican, a la vez, una atracción-alejamiento frente a la seducción-fascinación que provocan las marcas.

Ahora bien, junto a la publicidad que presenta los signos-marcas y que pretende subyugar a sus destinatarios en virtud de la escenificación de esa presencia, de la cual hemos hablado en la sección anterior, debemos hablar aquí de otro tipo de publicidad igualmente vigente en el marco de este semiocapitalismo: un género de publicidad que escenifica el acto de consumo como si se tratara de la decisión libérrima y carente de cualquier coerción del consumidor, disimulando de este modo la coacción que de hecho la publicidad ejerce sobre su destinatario... por el simple hecho de existir. Y si el primer tipo de publicidad suele corresponder a las marcas glamourosas que han reducido los productos en que se encarnan a la mera accidentalidad -de modo que el producto-soporte desaparece en la práctica engullido por el signo-marca-, el segundo tipo tiende a ser propio de aquellas marcas más prosaicas que están necesariamente próximas al producto que les sirve de soporte en virtud de su practicidad y que, como consecuencia de esta materialidad insoslayable, se encuentran continuamente sometidas al peligro de convertirse en genéricos (commodities) o ser devoradas por las marcas blancas.

Sea como sea, la marca, en cuanto encarnación del signo/mercancía, resulta inseparable de su doble publicitario. La publicidad constituye el lugar ideal -el espacio utópico, en términos de la semiótica narratológica de Greimas ${ }^{57}$ - donde los signos/mercancías son presentados ante el consumidor/fuerza productiva como su productor capitalista quiere que aquél los vea. Y es a través de esta escenificación como dicho consumidor se ve a sí mismo o bien disfrutando como producto que responde a una específica necesidad lo que es, en términos mayores o menores, fantasma de la mercancía -la cual, incapaz de incorporarse a la realidad que todos habitamos, ha de recluirse en la neorrealidad de la que habla Baudrillard ${ }^{58}$, y en la que todos los detergentes, aureolados por su respectiva marca, «lavan más blanco que ninguno»- o bien, en el extremo, ascendido a la presencia inmarcesible de una marca indeclinable, reducida a su pura mostración icónica, por mediación de la cual se ve integrado en un imaginario idealizado, en paridad de condiciones con toda clase de astros de la pantalla y de famosos del deporte.

De hecho, la relación intrínseca entre marca y publicidad está bien establecida por todos quienes se han ocupado del tema ${ }^{59}$. En este sentido, los inicios de la gran publicidad referida a marcas, que se va perfilando durante el último tercio del siglo XIX y las primeras décadas del XX, son testimonio inexcusable de los comienzos del propio semiocapitalismo: ya que es solo en la medida que los fabricantes de

57 VÁZQUEZ, I.; ALDEA, S. (1991): Estrategia y manipulación del lenguaje. Análisis pragmático del discurso publipropagandístico, Zaragoza, Universidad de Zaragoza, 92; GREIMAS; CoURTÈs (1979): Semiótica..., 428.

58 BAUDRILLARD (1970), La sociedad de consumo..., 150-154.

59 Véase, por ejemplo, EguizÁBAL, R. (1998): Historia de la publicidad, Madrid, Eresma Editorial \& Celeste Ediciones, 65. 
productos de gran consumo comienzan a experimentar la necesidad de diferenciar imaginariamente productos que son perfectamente homologables entre sí cuando deciden apelar directamente al consumidor mediante costosas campañas publicitarias que, según los parámetros económicos vigentes hasta entonces, entrarían claramente en la categoría de «gastos improductivos» ${ }^{60}$. Y la publicidad, cualquier publicidad, pasa a ser tan indispensable en el seno del semiocapitalismo como lo es la propia marca.

La publicidad es, en definitiva, el doble fantasmal a través del cual la marca, trasunto del signo/mercancía, se proclama realmente existente. Realidad siempre en precario, realidad continuamente amenazada que no trasciende su propia proclamación. Y por eso el universo publicitario está poblado de cadáveres de marcas que hace tiempo perdieron cualquier vestigio de realidad y que ahora se presentan a la mirada desacralizada del espectador con las costuras de su producción semiótica expuestas a la vista de todos. Presencias publicitarias que, paradójicamente, ya no proclaman ninguna presencia. Y que por ello son objeto de pura contemplación inmanente, en general de carácter estético, carente de cualquier trascendencia ${ }^{61}$.

Ahora bien, conforme la marca va perdiendo su fulgor de antaño -que, tal vez, solo se mantiene en la actualidad en el caso de las firmas glamourosas por mediación de las cuales el destinatario se ve integrado a sí mismo en un mundo de ficción-, el ciudadano de a pie se proclama crecientemente harto de publicidad. Dicho con otras palabras: la proclamación publicitaria corre el peligro de circular progresivamente en el vacío. Y de ahí que hoy se privilegie el uso de otros instrumentos menos abiertamente publicitarios, menos afectados por el deterioro de la propia convención publicitaria; para cumplir sin embargo el mismo efecto publicitario de escenificar la adhesión del consumidor a la marca y con ello hacer posible el funcionamiento de un semiocapitalismo en trance de naufragar, bajo las acometidas de la especulación financiera ${ }^{62}$.

\section{Conclusión}

Semiocapitalismo, marca y publicidad constituyen, así, los tres ingredientes de un conjunto estructural cuyo significado resulta inconcebible sin la presencia de los

60 Véase en este sentido la desconfianza con que dos autores dentro de la tradición marxista, Baran y Sweezy, contemplan lo que denominan «campaña de ventas». BARAN; SwEEZY (1966), El capital monopolista...

61 Esto es, se perciben en los anuncios de marcas caducadas las efigies de los modelos, la calidad de las ilustraciones o las tipografias, la ingenuidad de los ambientes escenificados o de las llamadas publicitarias, pero no la significación imaginaria a la que aquellos ingredientes semiolingüísticos daban forma.

62 En este sentido, el 11 de septiembre de 2001 marca sin lugar a dudas un hito en la transición entre dos eras. Cfr. CARO, A. (2005): «La fabricación del terron», en González Requena, J. et al. (eds.), El horror y la psicosis en los textos contemporáneos. Actas del I Congreso de Análisis Textual, Madrid, Asociación Cultural Trama \& Fondo (ed. en CD-Rom). 
demás. El semiocapitalismo se plasma, como hemos visto, en una producción semiótica que ocupa el lugar central que antes correspondía a la producción material y cuyo objeto es el signo/mercancía. A su vez, el signo/mercancía constituye la forma elemental de ese modo de producción-consumo, que se dota de existencia fáctica mediante su expresión semiolingüística que es la marca. Finalmente, la marca se reviste de presencia pública en virtud de la escenificación que le brinda la publicidad. Y así, estos tres componentes básicos del semiocapitalismo funcionan por mediación de los restantes y en virtud del apoyo que se brindan entre sí. De modo que el semiocapitalismo, como sistema económico-ideológico (ideología funcional o fría que resulta de la propia acción del sistema ${ }^{63}$ ), no podría funcionar sin la presencia de la marca y de la publicidad, y éstas justifican la primordialidad que han alcanzado a lo largo del siglo XX y mantienen a trancas y barrancas en los inicios de este siglo XXI debido al lugar capital que ocupan dentro de las estructuras del semiocapitalismo.

Pero esta descripción resultaría incompleta si no consideráramos la índole de la relación que une tales elementos entre sí. Y en este sentido, conviene tener muy claro lo siguiente: 1) el signo/mercancía no es simplemente una forma específica que reviste la mercancía en el seno del semiocapitalismo; se trata, por el contrario y como hemos visto con anterioridad, de un tipo de entidad económica que sustituye a la mercancía como núcleo del sistema capitalista y que oculta esta sustitución por medio de su simulación; de modo que, como consecuencia de ello, el objeto de la producción ya no son mercancías dotadas de su valor de uso y su valor de cambio, sino signos/mercancías resultado de una específica producción semiótica y provistos de un valor de consumo sustancialmente diferenciado del valor (trabajo) característico de aquéllas; lo cual permite sostener, como lo hemos venido haciendo a lo largo de este trabajo, que el semiocapitalismo constituye un sistema de producción cualitativamente distinto del modo de producción capitalista analizado por Marx; 2) la marca, en cuanto expresión semiolingüística del signo/mercancía, no se limita a explayar la significación de los productos (su valor de uso) tal como sería el caso si estuviéramos en presencia de mercancías: puesto que se trata, por el contrario, de signos/mercancías, los cuales implican, como acabamos de ver, un ejercicio de sustitución y en definitiva de suplantación de la mercancía, ello tiene su correlato semiótico con la presencia icónica de la marca y con su silencio con respecto a la cualidad simbólica del producto que está en su base; la marca, pura presencia icónica como corresponde a su entidad semiósica sin parangón con los significados convencionales, se encuentra así en consonancia con la negación de la naturaleza dialéctica de la mercancía que por su parte supone el signo/mercancía; de modo que si el signo/mercancía constituye en la práctica el modo como la producción capitalista aborta la mercancía como fruto del trabajo humano reduciéndola a su signo, la marca prolonga en el terreno semiótico esta expropiación recluyéndose en

63 Cfr.CARO (2010a), Comprender ..., 209. 
un silencio sígnico, en una constancia icónica carente de dimensión simbólica, donde cualquier diálogo, cualquier cuestionamiento, está erradicado de cuajo; 3) finalmente, la escenificación que la publicidad ejerce de la marca como trasunto del signo mercancía cumple un doble propósito: elevar el silencio de la marca a la escena pública, poblando el imaginario social de presencias hieráticas, privadas de espesor simbólico, que se imponen por su pura presencia icónica y frente a las cuales solo cabe adhesión incondicional, respeto sacro o el género de rebelión iconoclasta que ha derribado a lo largo de la historia a todos los ídolos sociales; y, en segundo lugar, escenificar la simulación que el signo/mercancía practica de la mercancía como si estuviéramos realmente en presencia de esta última: de modo que son usuarios «reales» los que ejercen en la publicidad acciones de consumo «reales», y deciden los productos «reales» que adquieren en función de sus necesidades «reales»... Con la única particularidad de que se trata en todos estos casos de una escenificación publicitaria, cuyo objetivo bien preciso es escenificar esta simulación; de modo que la sustitución de la mercancía por su signo que actúa el semiocapitalismo y que constituye su esencia pase lo más desapercibida posible a sus destinatarios.

Y es así, a través de esta acción coordinada de signo/mercancía, marca y publicidad como el semiocapitalismo funciona en la práctica. Hasta constituirse en un modo de producción-consumo cualitativamente diferenciado, como hemos mostrado en estas páginas, del capitalismo mercantil-productivista analizado por Marx.

\section{Referencias bibliográficas}

ALONSO, L.E. (2005): La era del consumo, Madrid, Siglo XXI de España.

BARAN, P.A.; SweEZY, P.M. (1966): El capital monopolista, México, Siglo XXI, 1968.

BATEY, M. (2008): Brand Meaning, Nueva York y Londres, Routledge.

BAUDRILlard, J. (1968): El sistema de objetos, México, Siglo XXI, 1975 (2ªd).

- (1970) La sociedad de consumo. Sus mitos, sus estructuras. Madrid: Siglo XXI de España, 2009.

- (1972): Crítica de la economía política del signo, México, Siglo XXI, 1974; BAUDRILLARD, J. (1973): Le miroir de la production ou l'illusion critique du materiales historique, Tournai, Casterman, 1977 ( $2^{\mathrm{a}}$ ed.).

- (1976): El intercambio simbólico y la muerte, Caracas, Monte Ávila Editores, 1980

BERARDI, F. Bifo (2003) La fábrica de la infelicidad. Nuevas formas de trabajo y movimiento social, Madrid: Traficantes de Sueños, 2003.

Berle, A.A.; MeAns, G.C. (1932): The Modern Corporation and Private Propiety, Nueva York, Harcourt, Brace \& World.

CARO, A. (1967): La sociedad de consumo, http://independent.academia.edu/AntonioCaro/Books/580765/La_sociedad_de_consumo

- (1993): La publicidad de la significación (Marco, concepto, taxonomía), tesis doctoral, Madrid, E-Prints Complutenses, 2002, 231-264; http://eprints.ucm.es/1788/ 
- (2002): «Del valor de consumo a la corporación como valor», Sphera Publica. Revista de Ciencias Sociales y de la Comunicación, 2, 65-79, Murcia, Servicio de Publicaciones de la UCAM.

- (2005): «La fabricación del terror», en González Requena, J. et al. (eds.), El horror y la psicosis en los textos contemporáneos. Actas del I Congreso de Análisis Textual, Madrid, Asociación Cultural Trama \& Fondo (ed. en CD-Rom).

- (2007): «Jean Baudrillard y la publicidad», Pensar la Publicidad. Revista Internacional de Investigaciones Publicitarias, 1(2), 131-146.]

- (2009a) «Prefacio», en Caro, A. (ed.), De la mercancía al signo/mercancía. El capitalismo en la era del hiperconsumismo y del desquiciamiento financiero, Madrid, Editorial Complutense, 4-15,

- (2009b): «Conclusión: El capitalismo en la era del hperconsumismo y del desquiciamiento financiero», en Caro, A. (ed.), De la mercancía al signo/mercancía. El capitalismo en la era del hiperconsumismo y del desquiciamiento financiero, Madrid, Editorial Complutense, 121135.

- (2010a): Comprender la publicidad, Barcelona, Blanquerna Tecnologia i Serveis.

- (2010b) «Editorial: Consumo y crisis capitalista», en Pensar la Publicidad, 4(1),11-16.

- (2011): «Marca y entidad semiósica», en Caro, A.; Scolari, C.A. (coords.), Estrategias globales. Publicidad, marcas y semiocapitalismo, DeSignis, 17, Buenos Aires, La Crujía Ediciones, 99-104.

CARO, A., ed. (2009): De la mercancía al signo/mercancía. El capitalismo en la era del hiperconsumismo y del desquiciamiento financiero, Madrid, Editorial Complutense, http://www.ucm.es/BUCM/ecsa/36254.php?id=356

CARO, A.; SCOLARI, C.A. (coords.) (2011): Estrategias globales. Publicidad, marcas y semiocapitalismo, DeSignis, 17, Buenos Aires, La Crujía Ediciones.

Chamberlin, E.H. (1931): The Theory of Monopolistic Competition, Cambridge, Mass.

CostA, J. (2004): La imagen de marca. Un fenómeno social, Barcelona, Paidós.

DoBB, M. (1946): Estudios sobre el desarrollo del capitalismo, Buenos Aires, Siglo XXI Argentina, 1971.

EGUIZÁBAL, R. (1998): Historia de la publicidad, Madrid, Eresma Editorial \& Celeste Ediciones.

EwEN, S. (1977): Captains of Consciousness: Advertising and the Social Roots of the Consumer Society, Nueva York, McGraw-Hill, 1977; trad. fr. Consciences sous influence. Publicité et genèse de la société de consommation, París, Aubier Montaigne, 1983.

FreY, A. W., ed. (1965) Marketing Handbook. Nueva York: The Ronald Press (2a ed.).

Fumagalli, A. (2007): Bioeconomía y capitalismo cognitivo. Hacia un nuevo paradigma de acumulación, Madrid, Traficantes de Sueños, 2010.

GALBRAITH, J. K. (1957): La sociedad opulenta. Barcelona: Ariel, 1963 (2ª ed.).

GoldMAn, R.; PAPSON, S. (1996): Sign Wars. The Cluttered Lansdscape of Advertising, Nueva York, The Guilford Press.

- (1998): Nike Culture, Londres, Sage.

GONZÁlEZ MARTín, J.A. (1996): Fundamentos para la teoría del mensaje publicitario, Madrid, Fondo de Cultura Económica.

GouX, J.-J. (2000): Frivolité de la valeur. Essai sur l'imaginaire du capitalisme, París, Blusson.

- (2011): «El precio de las cosas frívolas», en Caro, A. y Scolari, C.A. (coords.), Estrategias globales. Publicidad, marcas y semiocapitalismo, DeSignis, 17, Buenos Aires, La Crujía Ediciones, 15-23. 
Greimas, A.J.; CouRTÈs, J. (1979): Semiótica. Diccionario razonado de la teoría del lenguaje, Madrid, Gredos, 1982.

Hambleton, R. (1987): The Branding of America, Dublin, New Hampshire, Yankee Books.

JHALly, S. (1987): The Codes of Advertising. Fetichism and the Political Economy of Meaning in the Consumer Society, Londres, Frances Pinter.

LEACH,W. (1993): Land of Desire. Merchants, Power, and the Rise of a New American Culture, Nueva York, Vintage Books, 1994.

LIPOVETSKY, G. (2006): La felicidad paradójica. Ensayo sobre la sociedad de hiperconsumo, Barcelona, Anagrama, 2007.

MArtínez Tercero, M. (1991): «Mercadotecnia», en Benito A. (dir.), Diccionario de Ciencias y Técnicas de la Comunicación, Madrid, Ediciones Paulinas, 923-931.

MarX, K. (1867): El Capital. Crítica de la Economía Política, México, Fondo de Cultura Económica, $4^{\mathrm{a}}$ ed. 1966, tomo I.

PeIRCE, Ch.S. (1987): Obra lógico-semiótica, edición de A. Sercovich, Madrid, Taurus.

PONZIO, A. (2011): «La lógica de la publicidad y la ideo-lógica de la comunicación-producción global», en Caro, A. y Scolari, C.A. (coords.), Estrategias globales. Publicidad, marcas y semiocapitalismo, DeSignis 17, Buenos Aires, La Crujía Ediciones, 33-41.

Postone, M. (2003): Tiempo, trabajo y dominación social. Una reinterpretación de la teoría crítica de Marx, Madrid, Marcial Pons, 2006.

ROBERTS, K. (2004): Lovemarks. El futuro más allá de las marcas, Barcelona, Ediciones Urano, 2005.

Rossi-LANDI, F. (1968a): El lenguaje como trabajo y como mercado, Caracas, Monte Ávila, 1970.

- (1968b): «Las mercancías como mensajes», en Semiótica y estética, Buenos Aires, Nueva Visión, 1976, 103-109.

SEMPRINI, A. (1992): El marketing de la marca. Una aproximación semiótica, Barcelona, Paidós, 1995.

- (2005): La marca postmoderna. Potere e fragilità della marca nelle società contemporanee, Milán, FrancoAngeli, 2006.

StANTON, W.J. (1984 ): Fundamentos de mercadotecnia, México, McGraw-Hill, 1985 (3ª ed.).

STENBERG, E. (1999): The Economy of Icons. How Business Manufactures Meaning, Westport, Preager Publishing.

STRASSER, S. (1989): Satisfaction Guaranteed. The Making of the American Mass Market, Washington y Londres, Smithsonian Institution Press, 1995.

TEDLOw, R.S. (1990): New and Improved. The Story of Mass Marketing in America, Boston, Harvard Business School Press, 1996.

VÁZQUEZ, I.; ALDEA, S. (1991): Estrategia y manipulación del lenguaje. Análisis pragmático del discurso publipropagandístico, Zaragoza, Universidad de Zaragoza.

Wernick, A. (1991): Promotional Culture. Advertising, ideology and symbolic expression, Londres, Sage.

Williamson, J. (1979): Decoding Advertisements. Ideology and Meaning in Advertising, Londres y Nueva York, Marion Boyars.

Recibido: 30 de agosto de 2011

Aceptado: 10 de septiembre de 2011 